\section{PHYSICAL DEGENERATION AND SYPHILIS.}

Bx Liedtenant-Coloner F. J. LAMBKIN, R A.M.C. Officer Commanding Military Hospital for Venereal Diseases, Rochester Row, London.

Wiтн the question of physical degeneration at present so prominently before the public, the attention of the medical profession ought to be called more than ever to that disease which is, par excellence, a main factor in causing it. I mean, of course, syphilis. That this disease has been, and is, one of the chief causes of physical degeneration in England cannot be denied, and it is a fact that is acknowledged on all sides. This being so, the question arises as to what steps have been taken and what advance has been made in the treatment of this disease daring the last decade.

Preventive measures, such as the Contagious Diseases Act, have long since been abolished, and being, as it were, solely a political question, there is little use discussing them, with the exception of expressing one's opinion that it is a diggrace to the country that, in this era of civilization, such necessary means of prevention do not exist.

But, looking at the question from a purely medical aspect, one would like to know what advancement, if any, has been made in the treatment of syphilis in civil life in England during recent years. Undoubtedly, the actual means at our disposal for the treatment of this disease have vastly improved of late years when compared with what existed formerly. Has full advantage been taken of them?. No doubt the immediate signs and symptoms of syphilis have been enormously ameliorated, and the fearful cases of the disesse which one used to see are no longer seen, yet, judging from statistics, the after-effects of the disease on the population in general are as bad now, aye, and even worse, than hitherto, the returns of lunacy, general paralysis, tabes, etc., which are due, in all probability, to eyphilis, showing a terrible record.

The conclusion one is driven to is that whilst our mean of treating syphilis are far more reliable now to what they were of yore, yet that they have not been employed in that organized and systematic manner amongst the civil population which is our only hope of bringing about a permanent cure and thus destroying any chance of the ever-serious aftereffects of syphilis. (Vide evidence given before the Interdepartmental Commission on Physical Degeneration.)

In the army we have happily, during the last few years, succeeded not only in ameliorating the primary signs and symptoms of the disease, but from the table given here, which is taken from the recently-published Army Medical Reports for 1903 , it will be seen that of syphilitic cases the ratios per 1, 00 of invalids sent home, and more important still, of those requiring to be discharged from the service on acconnt of permanent unfitness, have been materially decreased, this result being undoubtedly mainly due to the organized and systematic method which has been to a great extent adopted during recent years in the army for deaing with gyphilis.

Table showing the ratio per 1,000 of the strength, and the average ratios for 10 years of venereal, among the European troops stationed at home and abroad during the year 1905.

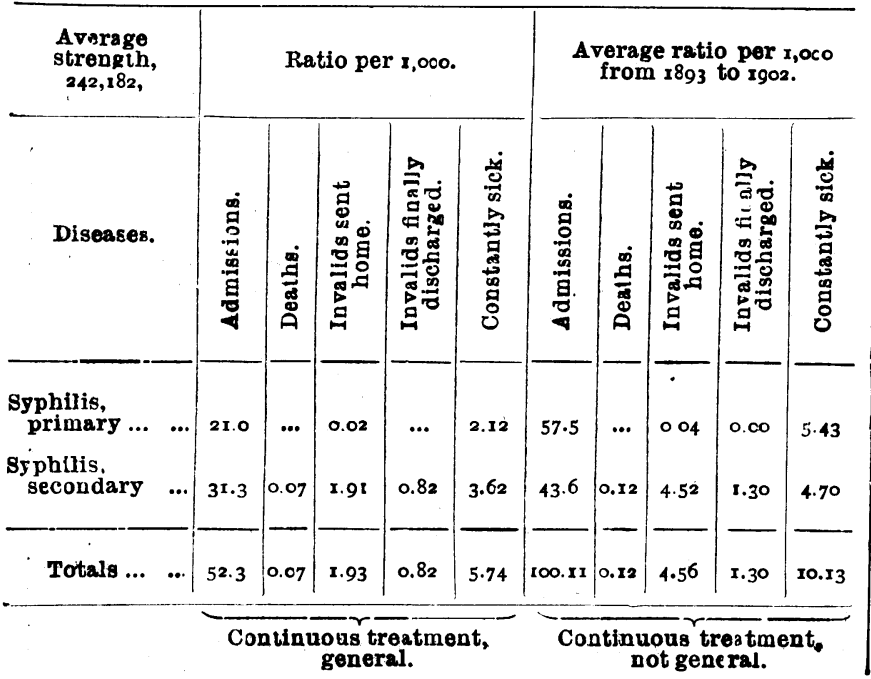

This system consists briefly as follows :

On the syphilitic patient being admitted into hospital, he is there treated until the active signs of his disease have disappeared. when he is discharged to his duty, but he is not lost sight of then, but, before leaving hospital, the character of his disease is explained to him, and the absolute necessity of continuous treatment extending over a long period is impressed upon him. He is advised to present himself at hospital on one day a week or fortnight, as the case may be. He is thus kept under observation and treatment for as long a time as the medical officer desires. The treatment, which for many reasons is undoubtedly the only practical one of carrying out either in the army or civil life, is the " intramuscular," and this is the one which has given by far the best results. By the intramuscular method is meant the injection of either the solnble or insoluble salts of mercury. The latter have the great advantage over the former of needing to be injected but once a week or fortnight, whereas the former, to be beneficial, must be injected four or five times a week. In the army the insoluble salts are preferably used, and generally in the metallic form, in the form of a cream, the latter is standardized, $m x$ containing gr. I of metallic mercury. The prnctice which I advise is that, after the patient is discharged from hospital, be should receive an injection of $\mathrm{mx}$, or $\mathrm{gr}$. 1 of mercury once a fortnight, and this done over a period of not less than three months, he is then given no injection during the following two months, but the injections are resumed and continued once a fortnight for the next three months. The patient continues under observation for another two months, and, if he has no recurrence of symptoms, the probability is that he is cured. There are certain essential details to be observed in carrying out this treatment into which it is unnecessary to enter here further than to remark that the patient's body weight is taken carefully and recorded each time he comes up for treatment. Whilst undergoing the above treatment out of hospital, the patient is enabled to carry on all his duties and is not incapacitated in any way.

Other modes of carrying out continuous treatment have been extensively attempted, such as giving the patient a certain number of mercurial pills, one or two of which he is directed to take daily, but this line of treatment, to my mind, need only be mentioned to be condemned, as, in nine cases. out of ten, patients either in the service or out of it will not take the medicine ordered once they are rid of pressing symptoms, partly through forgetfulness, very often wilfully.

By the intramuscular method of treating syphilis, be it either by the soluble or insoluble salts of mercury which are used, treatment of the disease can be carried out in that continuous manner which we know is necessary if we are to hope for a permanent cure, and itis through this treatment, to a great extent, that one is enabled to give the above encouraging table, and, with this line of treament.becoming more genera than it is, the above table can be much improved, and the ratios per, 000 men invalided either home or out of the service through syphilis reduced to a minimum.

Is there any reason why a similar method of treating syphilis should not be carried out in civil life?

When I have raised this question among professional friends, they have invariably said, "Oh, yes, you can carry out this method of treatment in the service, where you have discip'ine and can order your patients to attend for treatment." Now, I can say, from long experience, that this power of ordering patients to attend for treatment possesses no advantage whatever. On the contrary, $I$ find that in the army men come up for their treatment far more willingly when not ordered, but simply of their own free will, when they understand the necessity of undergoing continuous treatment.

One other reason which I have heard given as to why the intramuscular method cannot be carried on in civil life whilst patients are out of $h$ ospital is that the pain of the injections drives patients away. Amongst others, this was the opinion given by one of the London $\mathrm{L}$ )ck Hospital surgeons. Un the contrary, only a few weeks ago I had a communication on this subject from Dr. Henry FitzGibbon, Senior Surgeon to the Dublin Lock Hospital, in which he informed me that both his own experience and that of his colleagues is that the patients attending the Lock Hospital prefer the intramuscular (which has lately been adopted in that institution) to treatment by either the mouth or by inunction.

The treatment of syphilis amongst the civil population of England at present consists, as far as I can gather, of palliating the disease, not of endeavouring to curs it permanently, 
much the same as existed in the army until recent years. At the most, the only attempt of giving continuous treatment consists of giving mercury in some shape or form to be taken for a given time. Experience teaches us that the medicine ordered is in nine cases out of ten never taken with any rfgu. larity, or that when it is it is taken only when some acute sign of the disease appears. The consequence is that the patient. never getting any continuous treatment, never gets rid of his disease.

No wonder, then, that our lunatic asylums, etc., are fuller than ever.

I feel certain that the subject requires to be taken up seriously by the profession in England and the treatment of syphilis put upon an organized and systematic ground. Such a system is being carried out in Vienna with the best results, the method adopted there being very similar to that which we use in our army. In the Lancet of July 15 th, 1905, it was reported that in Paris notices have been postea up intorming the public of the place and time where they can receive treat ment. If this be neceseary in Paris, which is so well protected by the State from syphilis, how much more is it necessary in London and our large cities in the United Kingdom?

'To grapple with the treatment of syphilis among the civil population of England ought to be the chief object of those interested in that most burning question, the physical degeneration of our race.

SEVENTY-THIRD ANNUAL MEETING OF THE

\section{Britisti fflenical Association.}

Held at Leicester, July 24th, 25th, 26th, 27th, and 28th, 1905. PROCEEDINGS OF BECTIONS.

\section{SECTION OF NAVY, ARMY, AND AMBULANCE.}

Surgeon-Lieutenant-Colonel HenRy Walter Kialladar, M.R.C.S., President.

\section{SOME DYNAMIC AND HYDRO-DYNAMIC EFFECTS OF MODERN SMALL-BORE CYLINDRO.} CONOIDAL PRUJECTILES.

By Fleet Surgeon Charles M.arsh Beadneld, R.N.

Preliminary Remarks.

THE kinetic energy of a projectile is derived from the latent energy of an explosive within the chamber of a thermodynamic machine called the rifle. The actual work capable of being done by the modern small-calibre bullet upon the animal economy is from I 800 foot-pounds to 2,800 foot-pounds; in other words, it averages about 1 foot-ton.

When the volitation, conformation, and structure of the projectile are favourable from the surgeon's point of view, only a small fraction of this work is expended upon the tissues; from the big-game shooter's aspect these factors are only favourable when the whole of the energy of the projectile is represented as work done upon the anatomical elements. A knowledge of the remaining energies of the projectile is a sine qua non if we are to be able to predict the traumatic phenomena eventuating at varying ranges.

\section{Fixterior Ballistics.}

Owing to the resistance of the air, which varies directly as the square of the velocity for low and high velocities, and as the cube and sixth power for medium velocities, the energy of the projectile diminishes rapidly. Air resistance depends upon the density and the quantity and direction of motion of the atmosphere ; the shape, area, calibre, weight and velocity of the projectile.

At low velocities, the displaced air closes in immediately behind the base of the projrctile and a whistling noise is heard; at high velocities varua are formed behind the base, and a detonating sound, owing to collision of the columns of air, is heard.

A cap of condensed gas, i'o in. thick, covers the ogive of a projectlle in rapid motion through a gaseous medium. From the shoulder of such a projectile straight lines diverge posteriorly, symmetrically to the trajectory ; secondary divergent lines, forming somewhat more acnte angles, proceed from the basal cannelure, if there be nne; the angles formed by these lines with the trajectory diminish as velocity increases. Minute rotating spherules of air showing vertical motion line the path of the bullet.

Rotation of the Projectile About its Long Axis.

The colindro-conoidal projectile, revolving about its major axis, advances through the resisting atmosphere with this axis parallel to a tangent to the trajectory at the muzzle. Hence, at long ranges, the projectile strikes a horizontal plane " side on," at extreme ranges "base on." Atmospheric resistance being greater on the posterior than on the anterior half of the longitudinal mid-section of the projectile, counteracts to a slight extent this effort of the projectile to maintain its long axis parallel to the line of departure.

The revolution-speed of the bullet does not decrease so rapidly as the speed of translation, hence rotary phenomena are more marked at long ranges. In such cases the bullet may enter the body, but fail to emerge, rotating rapidly within the tissues until friction with them brings it to rest. That rotation plays a by no means insignificant rôle in the genesis of projectile traumatisms must be admitted when we consider that the muzzle rotary-speed of the modern bullet is from 2,000 to 4.000 revolutions per second.

\section{Penetrative Energy.}

Two bullets of different calibres, but possessing equal energies, do not transmit equal quantities of energo to equal areas of impact, the larger experiences more difficulty in perforation, it may even stop inside the body expending all its energy, whilst the projectile of more reduced calibre, doing less work upon the tissues, continues its course.

IMPACT.

The energy of the bullet on impact with the body is expended in deformation and heating of the tissues, in deformation and heating of the bullet, in imparting motion to, or modifying or arresting the motion of the tissues, in modifying or arrestivg the motion of the bullet.

Calefaction.

Heat phenomena, due to impact within the animal body, are very slight. On the other hand, heating of the projectile due to contact with enkindled gases, to friction with the "lands" of the rifle or with the atmosphere or with the ground during ricochet, is considerable, indeed quite sufficient to effectually sterilize it.

Deformation.

Deformation. which may be due to " stripping," ricochet, or impact with resisting tissues, has the double effect of enlarging the impact area and prolonging the projectile's duration of action. Deformations may be classified as :

I. Torsions.

2. Shears.

3. Lacerations.

4. Crushings-mushrooming.

5. Fragmentations.

6. Dislocations-partial or complete.

7. Bendings.

\section{Reciprocal action and Reaction of Projectile and} Tissurs.

In traversing the body the bullet acts upon tissues whose force of cohesion uniting the integrant molecules varies immensely, the more solid vigorously resisting disruption, the more liquid, in virtue of the mobility of their molecules, offering less opposition. Conversely, these different tissues vary in their mode of reacting upon the projectile. This mechanism of reciprocal ar.tion between projectile and tissues is merely one of force tran-mission, the work done by the bullet upon the body being equal to the force of cohesion which held together the now.displaced somatic molecules plus the energy communicated to them, for not only does the projectile destroy cohesion, it animates the dissociated particles, converting them into secondary projectiles.

Dynamic a ction of the Projectile.

When a hullet strikes a solid body, a series of molecular shocks radiate cont-wise from the point of impact to the molecules on the opposite side, these molecules swing back, and in this way the whole series is set oscillating. If the 